\title{
Desemprego juvenil: assimetria entre negros e brancos no mercado de trabalho na sociedade brasileira.
}

Marília Salles Falci Medeiros ${ }^{1}$

Resumo: Este artigo tem como objetivo analisar a desigualdade social entre os jovens negros no mercado de trabalho. Trata-se de uma velha situação de assimetria que abarca a população negra e branca, evidenciando que o processo de precarização do trabalho e o desemprego não são iguais para todos. Na estrutura social brasileira os negros sempre ocuparam situação de desvantagem social, que se pode definir como uma situação crônica, devido à persistência de sua vulnerabilidade em todos os indicadores sociais.

Palavras-chave: desemprego, juventude, mercado de trabalho.

\begin{abstract}
This article has as objective to analyze the social inequality it enters the young black population in the work market. This is about an old situation of asymmetry that incorporates the black and white population, evidencing that the process of precarização of the work and the unemployment are not equal for all. The social structure of Brazil the blacks population had always occupied situation of social disadvantage, that can be defined as a chronic situation, due to persistence of its vulnerability in all the social pointers.
\end{abstract}

Keywords: unemployment, youth, labor market.

\section{Introdução}

"Quando você se defrontar com argumentos cheios de remorsos, de que não existe racismo no Brasil, que o preconceito contra o negro é social e que os negros são complexados,pergunte ao interlocutor cheio de culpas....se ele já passou um dia de negro." ( Arnaldo Xavier-poeta afro-brasileiro)

${ }^{1}$ Programa de Pós-Graduação em Sociologia/PPGS, Universidade Federal Fluminense.

Latitude, vol. 6, n¹, pp.105-129, 2012

DOI: https://doi.org/10.28998/2179-5428.20120108 


\section{Desemprego juvenil: assimetria entre negros e brancos no mercado de trabalho na sociedade brasileira.}

Este artigo tem como objetivo analisar a desigualdade social entre os jovens negros no mercado de trabalho. Trata-se de uma velha situação de assimetria que abarca a população negra e branca, evidenciando que o processo de precarização do trabalho e o desemprego não são iguais para todos. Na estrutura social brasileira os negros sempre ocuparam situação de desvantagem social, que se pode definir como uma situação crônica, devido à persistência de sua vulnerabilidade em todos os indicadores sociais: saúde, educação, posição econômica, etc. Analisando a presença dos negros no mercado de trabalho esta situação torna-se evidente. $\mathrm{O}$ agravamento dessa situação será analisado neste texto através das duas situações sociais que contemporaneamente têm despertado grande interesse da sociologia do trabalho: o desemprego juvenil. Essa fragilidade fica ainda mais acentuada quando correlacionamos com o fator idade. Será necessário, portanto fazermos inicialmente uma abordagem do significado do desemprego juvenil e, em seguida, analisarmos a situação dos jovens negros dentro do perverso mecanismo de rejeição do jovem, sobretudo do jovem negro no mercado de trabalho das sociedades capitalistas contemporâneas.

\section{1) A Invenção do Desemprego}

A noção de desemprego emerge com o desenvolvimento da sociedade industrial e o emprego assalariado e se estabiliza com a criação de políticas institucionais destinadas ao tratamento do desemprego na sociedade. Há quem diga que esta noção é recente. No século XVIII não se falava de desemprego ou desempregado, mas de pobres, indigentes e mendigos. Falava-se da incapacidade, da falta de recursos de indivíduos em subvencionar suas necessidades. Não havia referências à privação de trabalho. Ao longo do século XIX, as classes populares foram percebidas pelos outros grupos sociais e pela ordem burguesa como "classes perigosas". (Chevalier, 1978). Mais que a pobreza, a ociosidade dos despossuídos é que perturbava e inquietava a sociedade. Isto explica que o atendimento público e social era marcado por uma lógica de punição. Ela não se limitava a distribuir recursos aos indigentes, mas também fornecer atividade aos sem recursos e aos ociosos, vagabundos. O trabalho não era visto como um direito, mas primeiro como um dever. Quem não trabalhava era visto como preguiçoso ou delinquente em todas as idades. (Chevalier, 1978)

No Brasil vamos observar essa mesma representação sobre o trabalho e a vadiagem. Lícia Valladares, no artigo "Cem anos repensando a pobreza (urbana) no Brasil", escreve sobre a mesma representação que se formou na Inglaterra vitoriana e na França, no que se refere à pobreza urbana. Essa representação será também elaborada pelas classes dominantes brasileiras, a partir do século XIX 
apresentando a oposição entre "trabalhadores" e "vadios" Segundo a autora, as classes dominantes, nessa época,

Fazendo uso de um discurso ideológico dualista (..) como que dicotomizavam o mundo: de um lado, o mundo do trabalho, da moral, da ordem; de outro, um mundo às avessas - amoral, vadio, caótico - que deveria ser reprimido e controlado para não comprometer a ordem. (...) (Valladares, 1991, p. 87).

Nesse sentido a expressão "classes perigosas" se referia basicamente às pessoas que se encontravam fora do mundo fabril; mais especificamente àqueles que eram criminosos, delinqüentes, ou simplesmente vagabundos e desordeiros, que viviam entre o cortiço e a rua, tentando impor a desordem Assim, a noção de "pobreza" remete ao mundo do não-trabalho, enquanto que a de "vadio" se referia ao homem pobre que não laborava (Valladares, 1991, p. 86).

Segundo Castel, a noção de desemprego como privação de trabalho, aparece com as transformações das relações de produção, ligando os proprietários e os trabalhadores e, mais precisamente, a codificação dessa relação através do salário. Robert Salais também assinala que a "invenção do desemprego" estava assim ligada à emergência de uma relação salarial, apoiada sobre um contrato de trabalho, institucionalizado e coletivo, marcando as transformações da sociedade industrial. ( R. Salais, ) Para Topolov não é fácil datar precisamente esta nova situação do trabalho, que se instala com o processo de produção capitalista na Europa , entre a metade do século XVIII e XIX. ( Topolov , 1994 , Apud Demaziére, pp. 5/6)

$\mathrm{O}$ reconhecimento da qualidade de quem não tem emprego se torna também, uma categoria jurídica. Esta noção vai definir a situação de trabalhadores que estão privados, excluídos do direito do trabalho. É precisamente o reconhecimento social das reivindicações dos indivíduos presentes no mercado de trabalho que vai se constituir o princípio da codificação do desemprego moderno. Essa consolidação da categoria vai impor-se depois da Segunda Guerra Mundial, juntamente com o movimento de planificação, cujo objetivo principal era resolver a grande penúria da mão - de- obra. A constituição de 1946 reconhece a emergência do desemprego moderno, ao definir o desempregado como o indivíduo disponível e a procura de emprego, o que implica a afirmação da responsabilidade estatal de garantia de pleno emprego. Como observa D. Demazière, "de dever, o emprego torna-se um direito, que se traduz em um estatuto codificado." ( Demazière, 2006. p.29)

Esse reconhecimento do desempregado como "sujeito de direito" implica também em um enquadramento social. A França, por exemplo, na década de 1967 criou uma agência, a ANPE-Agência Nacional para o Emprego, encarregada de assegurar o serviço público de colocação para os demandantes de emprego. Essa categoria permite um controle dos desempregados, já que na inatividade existe uma série de situações sociais. Assim o desemprego se define: (....) o desemprego é 


\section{Desemprego juvenil: assimetria entre negros e brancos no mercado de trabalho na sociedade brasileira.}

um período de inatividade mais ou menos prolongada, estruturada por uma busca de emprego, socialmente administrada. (Demazière, p. 31)

A codificação e a definição do desemprego, embora forneçam um quadro, com valor legal, não elimina sua dimensão política. Os desempregados são sempre objeto de classificações e de diagnósticos nos quais a parte de arbitrariedade não desapareceu. Demazière acentua que algumas faixas da população trabalhadora são eliminadas do mercado de trabalho e jogadas na periferia dos direitos sociais. (p.32) Já Claude Dubar acentua a explosão de estatísticas, sobretudo na crise contemporânea do capitalismo na Europa. Assim, são várias as instituições públicas e privadas a medir e declarar o que chamam de desemprego. Segundo o autor:

As estatísticas e analises concernentes ao desemprego dos jovens e sua evolução recente, são ao mesmo tempo abundantes, controvertidas e incompletas. Elas estão se tornando progressivamente um suporte essencial das demonstrações políticas. ( Dubar, 1987, p.15)

Margaret Maruani vem também acentuar o peso do social que não pode ser obscurecido pelo primado da economia na análise do desemprego:

"A distribuição do emprego na sociedade é repartição de um bem raro entre as categorias sociais; as opções que presidem esta divisão são mais frutos de uma fundamentação em termos de legitimidade social que de um cálculo econômico."(Maruani,2002. p.3)

Isto quer dizer que as políticas de emprego procedem da arbitragem entre os grupos sociais, são escolhas políticas, mais do que somente decisões econômicas. Para além da dimensão econômica do fenômeno, o desemprego juvenil tornou-se uma valiosa demonstração política dos governos e instituições em mostrar preocupações através de investimentos sociais no seu combate.

O problema do desemprego despertou um vigoroso debate público e teórico na Europa, que, com muito menos peso, entrou no Brasil. Para além das estatísticas e debates existentes sobre esta questão, nosso interesse é buscar refletir neste texto a significação social do desemprego juvenil em geral e o papel do jovem negro em particular, dentro do processo de rejeição do mercado trabalho contemporâneo. Observa-se, nas ultimas décadas, uma tendência internacional em acentuar a vulnerabilidade dos jovens ao desemprego. Importa também compreender quais os significados sociais dessa tendência, sobretudo quando atinge a juventude negra no Brasil. 
Marília Salles Falci Medeiros

\section{2) A Realidade Apresentada Pelos Dados}

Nos Anos de Ouro do Capital os jovens tinham acesso ao emprego como uma forma de transição entre escola e trabalho, um rito de transição entre a juventude e a idade adulta, que era realizado naturalmente nos 30 anos gloriosos que marcaram o fordismo na Europa. Com a crise, que teve inicio nos anos 1970, esse ritual de transição começa a ser rompido em uma escalada jamais imaginada na Europa. Assustou a todos as altas taxas do desemprego em geral e o desemprego juvenil particular em países como a França, que possuía um dos melhores sistemas de proteção social durante décadas, além de um sistema fortemente industrializado. No entanto, o que tem chamado mais a atenção do mundo é a persistência das altas taxas de desemprego nesses países. Observa-se uma crise econômica sem precedentes, chegando Mezzaros a afirmar que existe uma crise estrutural do sistema. Em 1995, três milhões de jovens franceses, com menos de 25 anos e disponíveis para trabalhar, estavam sem emprego. Em outros termos, eram mais ou menos quatro jovens entre 10 que permaneciam nessa situação. Recentemente uma pesquisa elaborada pelo governo alemão revelou que a Inglaterra, França, Suécia e Polônia, sem mencionar países como Portugal, Irlanda, Espanha e Grécia, apresentavam índices de desemprego para a população entre 16 e 24 anos igual ou superior a $20 \%$. A média no continente é de $20,5 \%$, a mais alta desde 1980. A crise se alastrou pela Europa e atingiu fortemente os jovens. Esses se tornaram os mais vulneráveis da população trabalhadora, juntamente com os migrantes dos países pobres. A Espanha chega a atingir $45 \%$ de desemprego, Itália, conforme um documento organizado pela OCDE e rapidamente lança milhares de jovens na informalidade e no subemprego. Já se fala de uma geração perdida, pois até os dias atuais, o desemprego na Europa é alto e persistente. Segundo especialistas que elaboraram o Documento da Organização para a Cooperação e Desenvolvimento Econômico (OCDE) o desemprego juvenil cresce mais que o dobro das taxas do desemprego adulto e a tendência é de que continue a crescer ainda mais. Anne Sonnet, analista econômica da OCDE e especializada em mercado de trabalho para os jovens e adultos, diz que a solução para a crise Européia não é visualizada em curto prazo e, por isso, a situação ainda vai piorar.

Os impactos do desemprego são tão significativos, que tem afetado, inclusive, o modo de viver dos jovens europeus. Devido aos preços elevados para aluguel ou compra de imóveis, o endividamento ao longo dos anos de formação acadêmica e a falta de perspectiva de emprego, observa-se uma forte reversão da tendência do processo de independência dos jovens, já cristalizado desde os anos 1970 naqueles países. Estes anos marcaram o auge da rebelião juvenil. Era a fase das "comunidades de habitação". Viver fora da companhia dos pais era expressão de posição política, libertação social e sexual e uma forma de protesto contra a 


\section{Desemprego juvenil: assimetria entre negros e brancos no mercado de trabalho na sociedade brasileira.}

família clássica. O jovem saía da escola com mais de 18 anos e ia morar sozinho. Até os anos 1980 era muito raro ver um jovem alemão, inglês ou francês, de mais de 20 anos, ainda vivendo com os pais. Neste quadro, os ingleses saiam de casas muito mais cedo que seus vizinhos franceses e alemães.

Este quadro tem mudado e segundo o Escritório Nacional de Estatísticas (ONS) $29 \%$ dos homens entre 20 e 34 anos vivem com os pais. Entre as mulheres, $18 \%$ a $28 \%$.

Nos últimos dois anos os estudos apontam que o desemprego na Inglaterra começa a afetar o modo de viver dos mais velhos. Segundo a ONS, ao menos 500 mil adultos entre 35 e 44 anos retornaram à casa dos pais nos últimos dois anos. $\mathrm{O}$ mesmo fenômeno vai ser encontrado na França. Na Itália ele adquire o nome de Mamone, derivado de mamma, indicando que ele não abandona o apoio materno. $\mathrm{Na}$ Espanha é denominado de $\mathrm{Ni}-\mathrm{Ni}$, referindo-se aos jovens que não estudam e nem trabalham. Cerca da metade dos jovens espanhóis não deixam o lar antes dos 34 a 40 anos. Pesquisas mostram ainda que esta geração não tem nenhum projeto e nem se sente envolvida socialmente. Na Inglaterra são denominados de Kidults (do inglês Kid +adults). Jogam video-game andam de skate, colecionam jogos e brincam. As pesquisas apontam que, além da infantilidade, tem-se observado que os jovens desses países estão também estendendo o tempo na escola e ampliando a formação universitária. A situação descrita é preocupante tendo em vista que o problema do desemprego provoca frustração e já se observou na França e na Inglaterra o aumento da de manifestações de protestos violentos além do aumento dos jovens em conduta de risco.

\section{3) As Explicações Sobre O Fenômeno Do Desemprego Juvenil em Geral}

Como explicar a vulnerabilidade juvenil? Será que a idade é um, fator determinante no mercado de trabalho? Todos os jovens são eles vulneráveis? Qual o papel da cor e sexo do jovem no aumento de sua vulnerabilidade? Essas questões não admitem respostas simples. Elas são objeto de um longo debate que trabalha com diferentes hipóteses e muitas causas podem, inclusive, estar relacionadas.

A literatura estrangeira é muito mais abundante sobre as análises do desemprego juvenil que a brasileira. Embora já tenhamos mais que uma preocupação com o problema ainda a produção sobre esta questão não é tão extensa. É importante de observar o caso da sociedade francesa. Foi criado naquele país mais que uma sociologia do desemprego juvenil, um sistema de pesquisas, estudos e publicações em diversas áreas, como sociologia, economia, pedagogia, política, serviço social, psicologia, com o objetivo de pesquisar as razões e características do desemprego juvenil. O interesse do Estado foi de subsidiar cientificamente as políticas públicas para o emprego de jovens. Vários 
profissionais, instituições foram contratados e também diversos dispositivos foram criados para dar cursos profissionalizantes aos jovens desempregados Toda essa política, visando análise, construção de políticas públicas e preparação profissional para inclusão dos jovens, teve início nos anos de 1980 e 1990 e, até o momento presente, não conseguiu estancar a avalanche do desemprego juvenil. Com mais de 2,8 milhões de pessoas desempregadas, segundo Bureau International Du Travail (BIT), a taxa de desempregados entre 15-24 anos atinge 22,7\%. Estão ainda com altas taxas, quatro em cada dez jovens estão no desemprego já se fala de uma geração perdida.

\section{4) Teorias Sobre o Desemprego}

Quando se fala do desemprego juvenil e suas origens, Sanchis afirma que a causa fundamental é a mesma que a do desemprego adulto: escassez de empregos. Como a intensidade não é a mesma nos dois casos, o autor propõe que devemos ir além das explicações gerais para se tentar compreender o que se passa particularmente no mundo jovem. ( Sanchis: 1999, 126)

Doeringer e Piore segmentam o mercado de trabalho em mercado interno e mercado externo. Pode-se também dizer, que está relacionado com a distinção entre mercado primário e secundário. E explica:

"O primeiro oferece empregos com salários relativamente elevados, boas condições de trabalho, possibilidades de promoção, procedimento oportuno e equitativo na administração das normas laborais e, sobretudo, estabilidade no emprego, Os empregos do setor secundário, pelo contrário, costumam ter baixas retribuições, condições de trabalho deficientes, possibilidades mínimas de promoção (...) implicando numa dura e arbitrária disciplina de trabalho, uma considerável instabilidade no emprego e uma grande rotatividade da mão de obra." (Piore, 1972, apud. Sanchis:1999,128) .

O que mais é acentuado no caso do mercado de trabalho secundário é a instabilidade do trabalhador. É no mercado secundário que se encontra também todas as formas de discriminação, que o empresariado utiliza e incentiva visando a segmentação entre os trabalhadores. Em fase de crise da economia acentua-e o desemprego e a oferta da força de trabalho aumentando as pressões no mercado primário e ampliando por isso a desocupação. 


\section{Desemprego juvenil: assimetria entre negros e brancos no mercado de trabalho na sociedade brasileira.}

M. J. Piore faz uma análise da economia dos Estados Unidos no período de Crise e da guerra do Vietnã. Esta análise pode ser aplicada na crise atual do capitalismo, pois explica muito bem a lógica da produção empresarial nesses momentos de enfraquecimento do sistema. Para o autor, as crises são momentos de grandes incertezas e o empresariado, para atender aos aumentos das demandas, adotam medidas que visam empregar a mão de obra em caráter apenas temporário, tendo em vista as instabilidades do mercado. A utilização da mão de obra juvenil passa a ser inserida nesse mercado secundário, de caráter temporário.

Para O. Galland, essas circunstâncias estão dando lugar à configuração de um mercado de trabalho juvenil com perspectivas inseguras e incertas de inserção profissional, incluindo aqui também os originários de classes médias, com diplomas pouco competitivos. Para o autor não se trata exatamente de descriminação dos jovens por parte das empresas, mas simplesmente de redução do volume de novas contratações. Assim o autor explica:

"As maiores dificuldades de ingresso na vida profissional não respondem a uma atitude discriminatória dos empregadores, mas são imputáveis ao déficit geral de empregos, assim como ao fenômeno de estabilização no emprego dos ativos já ocupados, A especificidade do mercado de trabalho juvenil não reside, pois aí; antes reside na utilização particular que as empresas fazem desse tipo de mão de obra, explorando as oportunidades de flexibilidade que lhes oferece." (Galland, p.65. Apud Sanchis1999, p. 138)

Nesse pensamento os empresários não estão discriminando os jovens. $\mathrm{O}$ desemprego nessa faixa etária é resultado de fenômenos mais gerais da economia, mais complexos do que a idade do trabalhador. Os jovens estariam cobrindo uma parcela degradada de mão de obra que antes eram ocupada por imigrantes ou minorias étnicas, visto que as empresas necessitavam desse tipo de trabalho secundário e possível de ser precarizado. (Galland, p. 65. Apud Sanchis, p.138)

Sanchis abre um debate sobre a produtividade do trabalhador juvenil. Será que o adulto é mais produtivo? Ele propõe refletir não só sobre a questão do custo do trabalho juvenil como também em relação à produtividade esperada desse trabalhador em relação ao adulto.

"No que se refere ao custo do trabalho juvenil e a sua esperada produtividade, pode-se desenvolver uma comparação com os adultos, argumentando nos seguintes termos:os custos da mão-de- obra têm um caráter cada vez mais fixo, o que faz com que as empresas contemplem as novas contratações como 
Marília Salles Falci Medeiros

se tratasses de um investimento em capital fixo,"(

Sanchis:1999, 135)

$\mathrm{Na}$ contratação dos jovens tem-se que pensar em vários fatores como os elevados custos salariais e os custos a dispensar pela empresa na formação dos jovens. Além disso, é esperada uma fraca produtividade aliada uma forte rotatividade, que é característica da mão de obra juvenil. Neste sentido, as incertezas sobre os custos e benefícios derivados da contratação do trabalhador juvenil podem agravar a situação das empresas. Frente a estas incertezas o empresariado prefere a contratação dos trabalhadores adultos, estando ele na possibilidade de poder escolher. Estas colocações do autor nos remetem à questão da produtividade do trabalho juvenil.

I. Frey compara essa situação dos jovens com o que acontece no mercado com a situação das mulheres em relação aos homens, para se avaliar produtividade. $\mathrm{O}$ autor acentua que ainda não está claro que existam diferenças relevantes entre os dois trabalhadores, sugerindo que podem existir preconceitos. Pode ser cultural, considerando-se a escolha do homem pode ocorrer devido à idéia que ele é mais produtivo que a mulher. Situação idêntica pode está ocorrendo em relação aos jovens e adultos. Nesta visão cultural, se prefere os adultos por acreditarem que são mais produtivos do que os jovens. (I. Frey, apud Sancchis, 1999)

Ainda com Sanchis, podemos concluir esta parte, enfatizando sua posição em relação a existência de um mercado de trabalho juvenil, $\mathrm{O}$ autor parte do princípio que a causa fundamental do desemprego juvenil é a mesma que o desemprego em geral, que é explicada pela escassez de empregos provocada pela desaceleração do ritmo de crescimento e pela debilidade da demanda de trabalho. Diante de uma oferta superabundante de trabalhadores, a demanda atua com critérios seletivos e alguns grupos - entre os quais os jovens - saem especialmente prejudicados devido a uma série de causas confluentes. (Sanchis, 1999. p,152) O que esta sendo enfatizado é deterioração em ritmo acelerado do mercado de trabalho, com a precarização do trabalho, a crise do Welfare State, custos altos dos salários, recriação do trabalho formal e tudo o que já foi exposto .

No Brasil, não se pode atribuir como causa do desemprego juvenil as mesmas que a literatura tem discutido e analisado nos países desenvolvidos. Aqui recebemos inegavelmente os efeitos das lógicas de crescimentos e mudanças tecnológicas provenientes dessas economias, assim como sofremos os efeitos das crises afetam profundamente aqueles países. Mas não podemos esquecer que o que move nossa economia são outros processos, tanto no crescimento e modernização tecnológica como nas crises do sistema produtivo. Questões que analisaremos mais à frente neste texto. Por ora será necessário abordar como alguns autores analisam as causas do desemprego juvenil em nossa sociedade.

Latitude, vol. 6, n¹, pp.105-129, 2012. 


\section{Desemprego juvenil: assimetria entre negros e brancos no mercado de trabalho na sociedade brasileira.}

Um dos mais destacados estudiosos desse tema é Márcio Pochmann. O autor manifesta uma grande preocupação com o problema do desemprego juvenil, indo além da mera explicação acadêmica e teórica sobre o problema. Assim, formulou projetos e programas para a geração de políticas públicas estratégicas que pudessem incluir os jovens pobres e desempregados, na Prefeitura de São Paulo. Em 2002 organiza um livro sobre esta experiência intitulado Desenvolvimento, Trabalho e Solidariedade - Novos Caminhos para a Inclusão Social. Mas é no texto A Batalha do Primeiro Emprego onde dirige mais diretamente suas análises para o jovem no mercado de trabalho. Também na obra recente intitulada Nova Classe Média o autor contribui para se entender a queda do desemprego e conseqüentemente a do desemprego juvenil no país. Para expor as razões que podem explicar o desemprego, Pochmann faz uma análise estrutural da sociedade.

Assim, divide a sociedade em vários momentos que expressam modelos produtivos diferentes conduzidos pelo Estado. A primeira observada entre as décadas de 1960 e 1990. Observa-se que, durante o período de 1930 a 1980, houve forte expansão do emprego assalariado, sobretudo com a carteira assinada e perda da importância do assalariamento informal e das ocupações não assalariadas. Nesse contexto, as condições gerais da inserção ativa do jovem no mercado eram menos desfavoráveis. De 1960 a 1980, o Brasil crescia 4,6\% ao ano. Mesmo com essa melhora observou - se que, no final da década, houve uma forte concentração de renda e uma piora da desigualdade social.

A partir de 1981 entramos na segunda fase de mudanças no Brasil. De 19741985 transição democrática lenta no país. Este período pode-se dizer que é um marco político importante para o país, para os trabalhadores não houve nenhum ganho econômico. Durante os anos 1990 a população jovem ativa juvenil cresceu em 1,3 milhões de pessoas, enquanto o país criou apenas 448 mil vagas. A consequência disso, é que o desemprego juvenil atingiu a quase 1,8 milhões de jovens, uma das taxas mais altas já observadas nos últimos 100 anos. Houve um movimento de destruição de vagas e um aumento da população ativa juvenil. A situação geral do trabalho regrediu consideravelmente (14\%) e se observa além do desemprego um enorme aumento da informalidade.

O autor observa que nos anos 1980 e, sobretudo a partir de 1990, o Brasil começou a regredir nas formas de contratação da mão de obra. A combinação de desemprego e desassalariamento consolidaram um cenário desfavorável aos trabalhadores, sobretudo aos mais jovens, mulheres e idosos. ( Pochmann, 2000.pp. 33-34). Isso é resultado da forma passiva como o Brasil se submeteu ao neoliberalismo, sistema econômico imposto de fora do país.

Entre 2004 e 2010, terceira fase, constata-se um processo de crescimento da economia, Ocorre crescimento da renda per capta dos brasileiros, do índice da situação geral do trabalho $(5,5 \%)$ e da participação do rendimento do trabalho na renda nacional $(14 \%$. Este desenvolvimento virtuoso reduziu o desemprego e 
Marília Salles Falci Medeiros

também refletiu no desemprego juvenil permitindo a redução da desigualdade. Neste terceiro período (Primeiro Governo Lula) o setor primário diminuiu, o secundário estabilizou e o setor terciário expandiu. Resultado: o setor de serviços se tornou o maior empregador do país. Os postos de trabalho gerados encontramse na base da pirâmide social e o salário mensal é de 1,5 salários mínimos. Isso significou um saldo líquido de 2 milhões de ocupações abertas por ano. Nos anos 2000, segundo Pochmann, ao todo foram gerados 108 mil vagas para quem não tinha remuneração e isso vai provocar acentuadamente a redução do desemprego juvenil. É no segmento profissional que a inserção ocupacional do jovem acontece mais tarde, geralmente, depois da conclusão dos estudos obrigatórios. O certificado poderá facilitar mais seu ingresso na atividade econômica. Ele costuma passar ao longo da vida ativa por diferentes posições ocupacionais acompanhadas por remunerações distintas e diferentes status profissionais. A escolaridade básica é cada vez mais importante para o seu ingresso no mercado de trabalho. Por não possuir experiência profissional acumulada, ainda que possa ter diploma, o jovem tem dificuldade para ingressar no mercado de trabalho (Pochmann:2012, 14-16)

É importante analisar as pesquisas empíricas sobre o tema do desemprego juvenil. Recentemente, uma pesquisa elaborada pelo Projeto URBAL - Políticas Locais de Prevenção da Violência mostra que, embora a literatura enfatize causas estruturais que analisam o desemprego juvenil, a pesquisa usando a metodologia de análises de caso apresenta uma série de resultados que são muito instigantes para o debate sobre o tema. Dialogando com a bibliografia especializada não nega as repercussões na classe trabalhadora das transformações e das novas tecnologias criando um novo padrão produtivo com o uso da robótica, automação, microeletrônica e telemática, produzindo uma forte redução da mão de obra. Mesmo sem negar a complexidade do referido processo de "desproletarização", esta aponta para a visão do empresariado brasileira. Nesta visão, as empresas parecem não perceber bem o papel que elas desempenham, no processo. Sobre esta questão, Carlos Roberto Mesquita aponta:

“O discurso do empresariado e de outros agentes do capital de que o desemprego é resultado da falta de capacitação não é verdadeiro, pois houve uma ampliação dos indices de escolaridade têm-se, atualmente, os jovens mais qualificados de nossa história." (Apud C.P.Mesquita, p.4)

Frente a esses cenários, as empresas precisam se conscientizar a respeito do papel que têm desempenhado tanto cs atores que contribuem para o desenvolvimento social, quanto os elementos que incorporam uma responsabilidade na mesma problemática social.

Latitude, vol. 6, n¹, pp.105-129, 2012. 


\section{Desemprego juvenil: assimetria entre negros e brancos no mercado de trabalho na sociedade brasileira.}

Os dados de campo da pesquisa revelam que as empresas percebem os programas e as estratégias para incentivar a inserção juvenil como uma ação de responsabilidade das empresas. Os empresários se queixam pela falta de sensibilização por parte do setor público a respeito do desemprego juvenil. Embora já existindo diversos programas que visam facilitar a inclusão do jovem ao trabalho, os empresários participantes da pesquisa do Projeto Urbal, em sua maioria, dizem não serem incluídos nas iniciativas do Programa Nacional do Primeiro Emprego, Programa Federal Jovem Aprendiz e também no âmbito do próprio Estado de Pernambuco. Assim, os empresários pesquisados expressaram: "Tem as políticas, tem o Primeiro Emprego, existe isso, mas ainda não pegou, não está sendo muito percebido, não há uma sensibilização".

Os empresários declaram que nunca foram notificados e convidados a participar dos Programas. Apontam ainda na contratação dos jovens, a necessidade de se ter referências para os contratados. A referência é uma forma de segurança e de maior confibiliadade. Apontam na pesquisa:

"Quanto mais pessoas conhecidas dos outros, melhor para a gente porque é uma pessoa que não vai dar problema". "Quem é bom, quem tem referência e trabalha direito está contratado. Então dessas pessoas que estão sobrando se a gente não tiver um cuidado grande na contratação, a nossa forma de se resguardar é procurando a pessoa que já conhecemos" ( Gerente de uma empresa de engenharia)

A pesquisa menciona ainda a criação de uma rede de contatos entre as empresas como instrumento de busca por pessoal e como forma de se resguardar. Ausência de qualificação, altos impostos, e falta de sensibilização emergem como elementos que dificultam as empresas em absorver os jovens no mercado de trabalho. Assim um empresário expressou suas dificuldades na empregabilidade dos jovens:" Todas as ações do governo que envolve empregabilidade sacrificam as empresas cada vez mais "..." "Não tem jeito, ou eu reduzo as despesas ou eu reduzo o pessoal."

Podemos concluir que embora a pesquisa seja um estudo de caso, não tendo grandes abrangências, nos aponta para a necessidade das empresas e o Estado trabalharem conjuntamente na redução do desemprego juvenil, aumentando os Programas e estratégias públicas de sensibilização das empresas. 
Marília Salles Falci Medeiros

\section{5) A Situação Do Desemprego Juvenil No Brasil Vista Através Dos Dados.}

Será necessária uma análise detalhada para se compreender o que está acontecendo com a sociedade brasileira, que apresenta mudanças em sua estruturação social. Torna-se necessário refletir com cuidado sobre os dados estatísticos para não se incorrer em análises superficiais que podem distorcer a realidade. Os dados gerais, publicados pelas últimas pesquisas realizadas pelo IBGE, apresentam uma tendência diferente das sociedades desenvolvidas. Vários sociólogos e economistas tentam analisar o processo que vem acontecendo na base da pirâmide social do Brasil. Convivendo há décadas com altas taxas de exclusão social, após ter passado por um processo de industrialização tardia e altas taxas de concentração de renda, o país começa a apresentar um recuo nas taxas de desemprego e também outros indicadores dão sinais de mudança.

Os números indicam que ocorreu uma considerável mobilidade social nos últimos anos, entre 2004 e 2010. A renda per capita dos brasileiros cresceu a uma média de 3,3\% e 32 milhões de pessoas ascenderam à categoria que alguns autores, apressadamente, têm denominado de nova classe média de classes média. São mais 19,3 milhões saíram da pobreza. Os dados da Pesquisa Nacional por Amostragem de Domicílios (Pnad) do Instituto Brasileiro de Geografia e Estatística (IBGE), divulgada no mês de setembro de 2012, mostram uma redução no índice de Gini, que mede a desigualdade de renda. $\mathrm{O}$ indicador, que vai de 0 a 1 , caiu de 0,521 em 2007 para 0,515 .

Foi o décimo recuo seguido em dez anos. A mesma pesquisa apresenta uma série de índices que recuaram diminuindo a desigualdade em vários setores. Os resultados da Pesquisa Nacional por Amostra de Domicílios (Pnad 2011) confirmam que a primeira década do século 21 no Brasil foi "inclusiva" do ponto de vista social, com robusta diminuição da desigualdade e redução da pobreza, na avaliação do Instituto de Pesquisa Econômica Aplicada (Ipea). O economista Marcelo Neri, recém-empossado presidente do IPEA, observa através da imprensa: “O Brasil está hoje no menor nível de desigualdade da história documentada, o índice de Gini (indicador que mede a desigualdade) foi 0,527 em 2011 - o menor desde $1960(0,535)$. quanto mais próximo de zero menor é a desigualdade."

Segundo Neri, a redução tem a ver com o crescimento da renda per capita nos diferentes estratos sociais. Entre 2001 e 2011, o crescimento real da renda dos 10\% mais pobres foi $91,2 \%$. Enquanto os $10 \%$ mais ricos, o crescimento foi $16,6 \%$. Na opinião de Neri, a melhoria da renda na base da pirâmide relativiza o tímido desempenho das contas nacionais (medido pelo Produto Interno Bruto - PIB). Desde 2003, a Pnad aponta que a economia brasileira cresceu 40,7\% (acumulado), enquanto a taxa do PIB foi $27,7 \%$ (acumulado). O primeiro dado mede a situação dos domicílios, o segundo indicador faz o somatório da riqueza produzida no país.

Latitude, vol. 6, n¹, pp.105-129, 2012. 


\section{Desemprego juvenil: assimetria entre negros e brancos no mercado de trabalho na sociedade brasileira.}

Não só as pesquisas do IPEA destacam o crescimento e a queda do desemprego no Brasil, mas também os dados da Pesquisa Nacional por Amostra de Domicílios (Pnad), divulgadas pelo IBGE apontam para mudanças no quadro social do país. O número de pessoas desempregadas no Brasil caiu 19,3\% entre 2009 e 2011.

A taxa de desemprego também caiu de $8,2 \%$ para $6,7 \%$ no período, atingindo o menor patamar, pelo menos, desde 2004. Segundo a gerente da Pnad, Maria Lucia Vieira, a grande redução do desemprego entre 2009 e 2011 reflete a recuperação econômica do país nesse período, depois da crise econômica. A Pnad aponta ainda para a queda do analfabetismo no país em relação aos dados de 2009, mas atinge ainda , 9,1\% da população com mais de 18 anos. A edição 2011 da Pnad aponta avanço no número de pessoas com oito anos ou mais de estudo. Cerca de 29 milhões de brasileiros $(17,4 \%)$ estudaram entre oito e dez anos, frente a $16,35 \%$ da pesquisa de 2009. Na faixa dos cinco aos 17 anos, havia no país cerca de 3,7 milhões de trabalhadores, o que representa uma redução de 597 mil (14\%) em relação ao Pnad 2009. Embora o trabalho infantil tenha diminuído no país, segundo a Pnad ainda temos mais de 700 mil crianças de 5 a 13 anos, trabalhando de forma ilegal. O salário médio mensal domiciliar per capita dos menores empregado é de $\mathrm{R} \$ 329$.

Também a pesquisa De volta ao País do Futuro do Centro de Políticas Sociais da Fundação Getulio Vargas (CPS/FGV), comprova mudanças positivas no país. Observam também a queda no índice de Gini o que permitiu o Brasil atingir em 2012 o menor nível de desigualdade desde 1960, apesar da crise na Europa.

Marcio Pochmann analisando esta importante alteração na estrutura econômica explica o crescimento do país:

“(...) a primeira década de 2000 encontra-se diretamente influenciada pelo impacto da estrutura produtiva provocada pelo retorno do crescimento econômico, após quase duas década de regressão neoliberal. O fortalecimento do mercado de trabalho resultou fundamentalmente na expansão do setor de serviços, o que significou a difusão de nove em cada grupo de dez novas ocupações com remuneração de até 1,5 salário mínimo mensal. Juntamente com as políticas de apoio às rendas na base da pirâmide social brasileira, como elevação do valor real do salário mínimo e massificação da transferência de renda, houve o fortalecimento das classes populares assentadas no trabalho." ( Pochmann, 2012, p.10)

O autor nos mostra que o movimento de expansão dos empregos de baixa remuneração absorveu um enorme contingente de trabalhadores excedentes 
gerados nos governos neoliberais anteriores. Como as novas ocupações são do setor de serviços, exigem pouca qualificação e limitada experiência profissional. Enormes contingentes de trabalhadores são recrutados da condição de pobreza permitindo o que Pochmann considera uma inegável ascensão social. Este crescimento inclusivo na base da pirâmide, que já conta com mais de 40 milhões de indivíduos, geraram uma discussão sobre a possibilidade de se denominar esses novos segmentos como pertencentes aos domínios da classe média. Neste sentido as observações de Pochmann são bastante esclarecedoras. Contrariando a visão de outros economistas e sociólogos, ele afirma que somente o rendimento, que permite a entrada destes grupos no mercado de consumo, não é suficiente para classificá-los como classe média. ( Pochmann, 2012)

Embora se verifique alterações de mobilidade ascendente, não se pode esquecer que a população sobrante ainda é muito grande no país. Para aqueles que ainda procuram uma nova colocação no mercado de trabalho, a espera por trabalho é longa e muito angustiante. De acordo com Instituto Brasileiro de Geografia e Estatística (IBGE), ainda existiam, no ano passado, 6,6 milhões de brasileiros sem emprego.

Embora o Brasil tenha melhorado em índices importantes, o país ainda está entre os 12 mais desiguais do mundo. Uma recente publicação aponta ainda para os números alarmantes que podem dimensionar a realidade do desemprego juvenil no Brasil. $\mathrm{O}$ estudo foi elaborado e coordenado pelo professor Adalberto Cardoso, do Instituto de Estudos Sociais e Políticos (IESP), da Universidade do Estado do Rio de Janeiro (UERJ), intitulado Juventude, desigualdades e o futuro do Rio de Janeiro. O professor teve por base os micro dados do Censo Demográfico de 2010, fornecido pelo do IBGE. Assim aponta:

"São 5,3 milhões de jovens, entre 18 e 25 anos, que estão fora da educação formal e do mercado de trabalho no Brasil. Um problema que atinge um em cada cinco jovens (ou 19,5\% dos 27,3 milhões de pessoas dessa faixa etária), (Cardoso,2012)

Pelos dados do pesquisador do IESP,

"o número de moças que fica em casa é quase o dobro do dos rapazes: respectivamente, 3,5 milhões e 1,8 milhão. Mas a maternidade não é a única explicação. O forte desalento, ajuda a entender os números alarmantes. Que ficam mais graves quando se leva em conta que, em 2010, ano do Censo, a economia brasileira cresceu 7,5\%.". ( Cardoso , 2012) 


\section{Desemprego juvenil: assimetria entre negros e brancos no mercado de trabalho na sociedade brasileira.}

Como acentua Cardoso, o contingente de 5,3 milhões de jovens inativos no Brasil ocorre num momento em que o país tem baixas taxas de desemprego e os empresários se queixam de escassez de mão de obra. Isto quer dizer que a diminuição do desemprego juvenil no Brasil não foi suficiente para incorporar o contingente de 5,3 e segundo a pesquisa este cenário pode ser ainda pior. Ao incluir os jovens que buscam trabalho, mas não conseguem, os 5,3 milhões saltam para 7,2 milhões. O gargalo, segundo o professor Fernando de Holanda Filho, da Fundação Getulio Vargas (FGV), está na baixa taxa de matrícula do ensino médio. Hoje, segundo ele, ao menos $50 \%$ dos jovens trabalham sem ter nível médio. Estes, quando vão para o mercado de trabalho, não conseguem se colocar. Esse cenário produz um desalento estrutural e se complica a cada ano. É um problema de longo prazo. Em uma entrevista publicada em O Globo, Neri se declara otimista com o futuro do Brasil:

"São dez anos de redução da desigualdade. E a alfabetização e o saneamento ainda são marcas de um Brasil do século XIX e deram um salto este ano. Eram indicadores que estavam andando muito devagar, a taxa de analfabetismo caiu bem, e o saneamento avançou. A renda domiciliar per capita mediana ( que fica na metade da pirâmide) aumentou 10 \%."

\section{6) A Inclusão do Negro no Mercado de Trabalho}

A primeira característica que distingue jovens no mercado de trabalho é a cor. Os negros no Brasil contemporâneo são ainda os mais vulneráveis ao desemprego que os brancos. Com aumento do desemprego em geral, os negros encontram-se em situação mais ainda degradante. A desvantagem deles em face ao emprego é antiga. Durante um longo período prevaleceu no Brasil o mito da democracia racial, segundo o qual o preconceito e discriminação contra o negro seriam um problema de estratificação social, ou seja, seria decorrente da posição socioeconômica inferior da população negra, herança do nosso passado escravista.

Uma perspectiva de análise mais recente, e menos otimista, assume que a inserção social de um indivíduo na sociedade é diretamente relacionada à sua cor, e que a persistência histórica da raça como princípio classificatório não deve ser encarada como herança do passado, mas como um mecanismo social de reprodução da desigualdade racial, servindo aos interesses do grupo racialmente hegemônico. Ou, em palavras mais simples, a posição sócio-econômica inferior da população negra seria decorrente de sua menor oportunidade de ascensão social e econômica em função do preconceito e discriminação raciais existentes na sociedade brasileira. ( Perpétuo.I.2000) 
Marília Salles Falci Medeiros

Uma série de estudos tributários dessa segunda abordagem tem documentado a segregação da população negra em dimensões variadas, tais como a distribuição espacial, o acesso à educação, a inserção no mercado de trabalho. (Ver, por exemplo, Hasenbalg, e Vale Silva (1988); Hasenbalg (1990) ). Estudos feitos por Hasenbalg, indicam também as dificuldades específicas para a população afro-descendente, com relação a ascensão social quando afirma que estes "...sofrem uma desvantagem competitiva em todas as etapas do processo de mobilidade social. Suas possibilidades de escapar às limitações de uma posição social baixa são menores que as dos brancos na mesma origem social, assim como são maiores as dificuldades para manter as posições já conquistadas". (Hasenbalg e Silva, 1988, p. 177)

Nos estudos de José Pastore e Nelson do Valle Silva (2000), podemos verificar que a mobilidade social ascendente para a população negra continua limitada. Dentre os fatores negativos, gerados pela sociedade racista, está a dificuldade de conversão da educação formal em posições ocupacionais compatíveis. Para os dois autores, as informações que coletaram

“... sugerem que os não-brancos experimentam uma desvantagem na conversão de sua educação formal em posições ocupacionais, o que pode estar vinculado a processos de discriminação racial no mercado de trabalho." (Pastore e Silva, 2000, p. 95)

Recentemente foi lançada em Maceió, a primeira etapa do plano de prevenção à violência contra a juventude negra. O Plano Juventude Viva foi elaborado pela Secretaria de Políticas de Promoção da Igualdade Racial da Presidência da República e pela Secretária - Geral da Presidência da República, por meio da Secretaria Nacional de Juventude, com o apoio de um conjunto de ministérios e participação ativa da sociedade civil. Isto porque a situação social dos jovens negros no Brasil é pior do que a da juventude branca. Segundo dados daquela secretaria, o homicídio é a principal causa de morte de jovens de 15 a 29 anos no Brasil. Isso se agrava ao constatarmos que os jovens negros são as principais vítimas. Em 2010 foram assassinadas quase 50 mil pessoas no país, sendo mais da metade delas jovens (53,3\%), dos quais 76,6\% eram negros e $91,3 \%$ homens, segundo os dados do Sistema de Informações de Mortalidade do Ministério da Saúde. Entre 2001 e 2010, mais de 270 mil jovens foram vítimas de homicídio no país. Trata-se de um cenário de violência extrema, de violação flagrante de direitos humanos, que atinge, sobretudo os jovens negros. Já se fala em situação de extermínio do jovem negro e pobre devida as absurdas taxas de mortalidade, encarceramento, envolvimento com drogas resultando em violência de todo tipo.

Latitude, vol. 6, n¹, pp.105-129, 2012. 


\section{Desemprego juvenil: assimetria entre negros e brancos no mercado de trabalho na sociedade brasileira.}

Ao dirigirmos a reflexão para o mercado de trabalho também se comprova aqui persistência da desigualdade racial no Brasil. É importante observar que os jovens negros que estão estudando, se comparado com os jovens brancos na mesma condição, se encontram majoritariamente excluídos do mercado de trabalho. Será importante analisar algumas estatísticas atuais nas quais o DIESSE /SEADE divulgam sobre a pesquisa realizada no período de 2004 - 2008, revelando alterações na desigualdade social entre negros e brancos no país.

TAXAS DE DESEMPREGO, POR COR NAS REGIÕES METROPOLITANAS E DISTRITO FEDERAL 2004-2007 (EM \%) TABELA 32

\begin{tabular}{|c|c|c|c|c|c|c|c|c|c|}
\hline \multirow{2}{*}{$\begin{array}{l}\text { Regiõ } \\
\text { es } \\
\text { Metropolita } \\
\text { nas }\end{array}$} & \multicolumn{4}{|c|}{ Negro } & \multicolumn{5}{|c|}{ Não Negro } \\
\hline & $004^{2}$ & 005 & 006 & 007 & 004 & 005 & 006 & 0 & 20 \\
\hline $\begin{array}{l}\text { São } \\
\text { Paulo }\end{array}$ & 22,5 & 0,8 & 9,1 & 7,6 & 6,4 & 4,7 & 3,9 & , & 13 \\
\hline $\begin{array}{l}\text { Porto } \\
\text { Alegre }\end{array}$ & 23,1 & 0,3 & 0,3 & 7,4 & 4,9 & 3,6 & 3,3 & 1 & 12 \\
\hline $\begin{array}{c}\text { Belo- } \\
\text { Horizonte }\end{array}$ & 21,2 & 8,7 & 5,7 & 4,1 & 6,4 & 4,0 & 1,5 & 7 & 9, \\
\hline $\begin{array}{ll}\text { Salva } \\
\text { dor }\end{array}$ & 26,6 & 5,5 & 4,5 & 2,7 & 8,1 & 7,2 & 7,8 & 6 & 15 \\
\hline Recife & 23,9 & 2,6 & 2,0 & 0,5 & 1,1 & 1,2 & 8,9 & , & 17 \\
\hline $\begin{array}{l}\text { Distrit } \\
\text { o Federal }\end{array}$ & 22,5 & 0,0 & 9,9 & 9,0 & 7,5 & 7,0 & 6,7 & , & 15 \\
\hline
\end{tabular}

Fonte: DIEESE/Seade,TEM/FAT e convênios regionais, PED- Pesquisa de Emprego e Desemprego /pag.54

Segunda a pesquisa, "os analfabetos negros possuem taxas de desemprego maiores que os não-negros. Mas, a situação se repete igualmente para os trabalhadores e trabalhadoras negros com nível superior". http://www.dieese.org.br/esp/conscinegra.pdf

Segundo o levantamento, a taxa média de desemprego dos negros em 2010 foi de $14 \%$, ante $10,9 \%$ dos não negros. O Dieese e o Seade informam que essa diferença vem diminuindo nos últimos anos. Do total de ocupados, 7,4\% eram trabalhadores domésticos, mas essa proporção sobe para 10,8\% entre os negros e cai para 5,7\% entre os demais grupos. A proporção de negros também é maior na construção civil ( $8,8 \%$ do total de ocupados negros, ante 5\% entre os demais). Mas os números também mostram alguma redução de diferenças na inserção dos assalariados no mercado. Proporcionalmente, os ocupados negros estavam mais 
representados em relação aos empregos com carteira (50,9\%, ante $50 \%$ dos não negros). Já a proporção de assalariados negros sem carteira era de $11,7 \%$, ante $11 \%$ dos não negros. Entre os autônomos, a proporção é próxima (16,5\% para negros e $15,9 \%$ para não negros). Mas a diferença sobe no serviço público: $8,4 \%$ dos ocupados não negros estão nos serviços públicos, ante $6,2 \%$ dos ocupados negros. "A explicação para essa diferença possivelmente tem origem no fato de mais da metade dos assalariados públicos possuírem grau de escolaridade superior. Essas características, associadas ao fato de que atualmente o ingresso no setor público se dá principalmente por meio de concursos, permitem inferir que a subrepresentação de negros nesse setor deve-se muito mais a suas históricas dificuldades de acesso aos níveis mais elevados de ensino do que a eventuais ações discriminatórias de que possam ser vítimas." ( DIEESE/SEADE)

Comparando as taxas desemprego entre jovens por sexo e Raça, os dados do DIEESE/SEADE nos mostra que nos anos 2000, observa-se em todas as regiões metropolitanas pesquisadas, uma taxa de desemprego superior entre os negros e entre as mulheres de ambos os grupos raciais. A maior taxa de desemprego ocorre na Região Metropolitana de Salvador. Conforme demonstram as tabelas à baixo. Os negros desempregados são aproximadamente $30 \%$ e os não-negros $21 \%$ (Tabela 12).

Tabela12

\begin{tabular}{|c|c|c|c|c|c|c|}
\hline \multirow{3}{*}{$\begin{array}{c}\text { Regiões } \\
\text { Metropolitanas }\end{array}$} & \multicolumn{5}{|c|}{$\begin{array}{l}\text { TAXAS DE DESEMPREGO, POR SEXO E } \\
\text { RAÇA NAS REGIÕES METROPOLITANAS DO } \\
\text { BRASIL/2000 (EM \%) }\end{array}$} & \\
\hline & \multicolumn{3}{|c|}{ Negro } & \multicolumn{3}{|c|}{ Não Negrc } \\
\hline & $\begin{array}{ll} & \text { T } \\
\text { otal } & \end{array}$ & $\begin{array}{r}\mathrm{H} \\
\text { omens }\end{array}$ & $\begin{array}{l}\mathrm{M} \\
\text { ulheres }\end{array}$ & otal & mens ${ }^{\text {Ho }}$ & $\begin{array}{l}\mathrm{M} \\
\text { ulheres }\end{array}$ \\
\hline $\begin{array}{l}\text { Belo- } \\
\text { Horizonte }\end{array}$ & 20,7 & 9,1 & 622 & 6,5 & $\begin{array}{ll} & 14, \\
0 & \end{array}$ & $\begin{array}{ll} & 19, \\
6 & \end{array}$ \\
\hline $\begin{array}{l}\text { Distrito } \\
\text { Federal } \\
\end{array}$ & 21,0 & 1,4 & 25 & 7,1 & 14 & 20, \\
\hline $\begin{array}{l}\text { Porto } \\
\text { Alegre }\end{array}$ & 25,2 & 3,2 & 27 & 6,8 & 14 & 19 \\
\hline Recife & 21,8 & 9,0 & 25 & 9,2 & 16 & 22 \\
\hline Salvado & 29,4 & 6,8 & 32 & 9,0 & 15 & 22 \\
\hline Paulo $^{\text {São }}$ & 22,7 & 9,6 & 26 & 6,5 & 13 & 20 \\
\hline
\end{tabular}

Fonte: DIEESE/SEADE e instituições regionais. PED - Pesquisa de Emprego e Desemprego Elaboração: DIEESE Obs.: Dados referentes a janeiro a junho de 2000. 


\section{Desemprego juvenil: assimetria entre negros e brancos no mercado de trabalho na sociedade brasileira.}

Para analisar esta situação de desigualdade vivida pelos jovens negros no Brasil e, sobretudo no mercado de trabalho, não se pode desconectá-la do lugar que estes ocupam na estrutura da sociedade, como resultado da configuração das relações raciais e do preconceito fortemente existente ainda no país. $\mathrm{O}$ debate teórico sobre a existência do racismo no Brasil não é recente e toda a literatura produzida vem afirmando a persistência da desigualdade racial no país. Como afirma Nelson do Vale Silva as "evidências não deixam dúvidas de que o mercado de trabalho não é cego para a cor, nem para o sexo, remunerando melhor os trabalhadores "brancos" por comparação aos pretos e pardos. ( Valle Silva,2000)

No Brasil generalizou-se uma crença de que um trabalhador ao adquirir mais escolaridade e acesso a uma boa formação profissional tem maiores oportunidades no mercado de trabalho. Silva demonstra em suas pesquisas que, se comparado os trabalhadores negros com os jovens brancos no mesmo grau de escolaridade, os brancos são mais bem remunerados e têm maiores oportunidades. Para Silva, o que explica esta situação de descriminação do negro, está sedimentada no que o autor constata na existência de "ciclos de desvantagens cumulativas"(.....), ou seja as desigualdades de rendimentos refletem em outras esferas da vida do trabalhador, resultando em processo de trocas desigual com os brancos. Os "não brancos" estão expostos a chances menores de ascensão social e, por isso, eles terão dificuldades maiores para ascender socialmente. A este respeito Ricardo Henriques afirma: "É possível dizer que a pobreza tem cor. A pobreza no Brasil é negra." (Henriques, 2001)

A desigualdade deriva principalmente da forte concentração de renda no segmento mais rico da sociedade, excluindo a base da sociedade onde situa os negros. Estes argumentos reforçam as hipóteses de Valle Silva uma vez que o autor destaca várias dimensões da desigualdade racial no Brasil. $\mathrm{O}$ autor chega a apontar que mesmo que os negros cheguem até a participar da riqueza país, como empresário ou outras ocupações, sua representação é ainda de participantes minoritários, se comparado com não negros na mesma situação social.Os brancos são mais ricos e mais desiguais. Os negros, mais iguais e mais pobres. Henriques aponta para a situação da escolaridade de brancos e negros, que, por sua vez, nos expõe com mais nitidez ainda para a inércia do padrão de discriminação racial. Explica o autor:

“(...) apesar da melhoria nos níveis médios de escolaridade de brancos e negros ao longo do século, o padrão de discriminação, isto é, a diferença de escolaridade dos brancos em relação aos negros, mantém-se estável entre as gerações. Reconhecendo a importância da educação na constituição da subjetividade e da identidade individual, inferimos com 
facilidade o ônus para a população negra e para a sociedade como um todo da manutenção desse padrão de desigualdade."( Henriques, 2001)

Esse argumento vem a explicar as origens dos ciclos de desvantagens cumulativas, uma vez que a educação reforça a situação de inferioridade social e os prejuízos acumulados pela população negra. Contudo as diferenças entre negros e brancos não são imutáveis. Os indicadores sociais apresentados por um grupo de pesquisadores do IPEA apontam para uma diminuição das desigualdades raciais entre 1995 e 2005. Segundo Ricardo Paes de Barros o secretário de Assuntos Estratégicos da SAE, "os negros aumentaram. Quase $80 \%$ do aumento na classe média referem-se à população negra",

Com esse aumento, a representatividade entre negros e brancos na classe $\mathrm{C}$ ficou equilibrada. Um total de $53 \%$ da classe média é formado por negros e $47 \%$ por brancos. O estudo registra que esse equilíbrio, no entanto, não significa que as desigualdades raciais foram superadas, uma vez que perduram nas demais classes. Na classe alta, $69 \%$ são brancos e $31 \%$, negros e na classe baixa $69 \%$ são negros e $31 \%$, brancos

Esta situação é confirmada pelas análises do professor Marcelo Paixão:

“(......) pode-se dizer que houve uma mudança nos patamares de rendimento dos grupos de cor ou raça, mas sem mudar essencialmente o modo pelo qual os distintos contingentes chegam ao mercado de trabalho. Assim, segue existindo maior probabilidade de uma pessoa de pele clara ter acesso aos postos mais prestigiados, o contrário ocorrendo com as pessoas de pele escura.( Paixão, 2012 12:45 )

Mais á frente ele conclui:

"O enfrentamento das desigualdades no mercado de trabalho envolve desde o investimento na educação, para proporcionar uma formação técnica e profissional, até políticas de ação afirmativa no setor público e privado. A redução das desigualdades raciais precisa ser vista como um objeto a ser perseguido pelo Estado e por toda sociedade. Infelizmente, isso não acontece no mercado de trabalho e demais espaços da vida social, contribuindo para que as posições desvantajosas das pessoas negras na sociedade brasileira se prorroguem indefinidamente .( Paixão, 2012 12:45 ) 


\section{Desemprego juvenil: assimetria entre negros e brancos no mercado de trabalho na sociedade brasileira.}

Como já foi analisada, também a pesquisa do DIEESE, tem mostrado nos últimos anos, aumento da contratação formal, isto é, crescimento mais intenso do assalariamento com carteira de trabalho assinada. Contudo, neste último ano 2008, destaca-se, ainda, a proporção menor desta forma de contratação entre os negros $(68,3 \%)$ e maior entre os não-negros (72,1\%).

Como acentua um estudo do IPEA. $76 \%$ da renda das famílias advém do trabalho no Brasil o que quer dizer que este é o principal determinante da renda domiciliar. O Trabalho é também fonte de socialização e construção identitária. O estudo do IPEA mostra ainda, que houve uma melhoria na situação do trabalhador negro em relação ao salário. Em 2005, o trabalhador negro auferiu tão somente $53, \%$ do que recebeu um trabalhador branco. Houve melhoria neste indicador, uma vez que em 1995 o negro recebia 48,3\% do salário de um branco e, em 2001, 49,7\%. (Baro, D, Soares, S. IPEA/ 2009, p.100).

Estas melhorias são importantes, mas por enquanto bem modestas. Como aponta o estudo, a desigualdade entre negros e brancos continua sendo um enorme desafio para os governos e para a sociedade brasileira em geral.

Hoje o acesso ao ensino fundamental encontra-se essencialmente universalizado no Brasil, tanto para negros como para brancos. O estudo do IPEA esclarece que embora o acesso esteja universalizado a esse nível de ensino, uma vez que as crianças negras tendem apresentar maiores taxas de evasão escolar. Freqüentar a escola não significa adquirir escolaridade uma vez que é de baixa qualidade e existe um grande índice de reprovação. Contudo a boa notícia é que o acesso a creche e a pré-escola vêm aumentando consideravelmente no país.

Quando o estudo do IPEA se aproxima do segundo ciclo é aí que se observa processo de exclusão do negro quanto ao acesso da educação. Em 2005 a taxa de matrícula entre jovens negros e negras de 11 a 14 anos foi de $68 \%$ quando se supõe as matrículas serem universais. Os outros $32 \%$ já desistiram ou encontram-se ainda no primeiro ciclo do ensino fundamental enfrentando a repetência, sem nenhuma perspectiva para entrar no século XXI. A diferença atual entre negros e brancos nesta situação hoje é de 15 pontos, o que aponta para uma notável melhoria quando há dez anos era de 27 pontos. No ensino superior os negros têm que enfrentar a barreira do vestibular. A imprensa tem notificado os resultados do Censo da Educação Superior de 2011, divulgados recentemente. Segundo o censo, em 1997 os negros representavam 4\% das matrículas na etapa do ensino superior. No ano passado, esse percentual subiu para quase $20 \%$ dos que freqüentam ou já concluíram a graduação. Constata-se, portanto que a participação de negros e pardos no ensino superior no Brasil aumentou. Mesmo assim, o índice ainda é considerado baixo, já que negros e pardos representam mais de 50\% da população brasileira segundo o Censo 2010 do Instituto Brasileiro de Geografia e Estatística (IBGE). O objetivo, agora, é tornar a participação deles no nível superior proporcional à do Censo, explicou o ministro da Educação, Aloizio Mercadante. O 
aumento é atribuído a fatores como a diminuição da população pobre nos últimos anos e as políticas de indução de crescimento educacional. É o caso do Programa Universidade para Todos (ProUni), do Plano de Reestruturação e Expansão das Universidades Federais (Reuni), do Financiamento Estudantil (Fies) e dos programas de cotas raciais existentes em algumas instituições e das cotas sociais. O Ministro da Educação Aluísio Mercadante reconheceu em uma de suas entrevistas recente, que embora os negros e pardos já possuam representação nas universidades, este índice é ainda muito baixo.

Não se pode esquecer que tanto os negros como os brancos foram beneficiados com o aumento das vagas ao ensino superior só que a taxa de crescimento da década é maior para os brancos. O anúncio do aumento no número de pretos e pardos matriculados no ensino superior ocorre um dia após a publicação do decreto que regulamenta a Lei de Cotas Sociais (Lei no 12.711), que define a destinação de 50\% das vagas de universidades federais a alunos da rede publica até 2016. Já nas próximas seleções as instituições vão ter de oferecer $12,5 \%$ das vagas a esse público.

Outra melhoria da situação do negro está representada pelo nível de rendimento entre brancos e negros. Segundo o IPEA um trabalhador negro, auferiu, em média em 2005, tão somente $53,3 \%$ do que recebeu um branco. A melhoria desse indicador fica expressa, uma vez que em 1955 um negro recebia 48,3\% de salário de um branco, e em 2001, 49,7\%. O estudo do IPEA atribui a queda do hiato salarial entre negros e brancos, a queda na discriminação praticada no mercado de trabalho e em parte também a redução no hiato educacional. O resultado segundo o estudo é que a renda domiciliar aumentou mais entre os negros que entre os brancos (IPEA, 2009. pp.100-105).

\section{Conclusão}

Os dados têm mostrado que há uma mudança de rumo na condução da administração das políticas sociais no Brasil. Para concluir seria bom citar novamente o Prof. Marcelo Paixão que também reconhece alguns avanços sobre as questões do negro na sociedade brasileira. Assim ele observa em uma de suas inúmeras palestras:

"Independente do Estatuto da Igualdade Racial, as cotas, uma medida tática necessária para combater o racismo, a questão quilombola, o genocídio da população negra, as politicas para as religiões de matriz africana e as desigualdades alinhavadas pela parelha de classe e raça são desafios que precisam de políticas e de formulação, num movimento de alcance nacional e articulado com os movimentos negros e sociais, para ter eficácia e condição funcional e orgânica na 


\section{Desemprego juvenil: assimetria entre negros e brancos no mercado de trabalho na sociedade brasileira.}

superação do racismo. Cresce, assim, o desafio conjunto dos movimentos negros e do PT." ( Paixão,2012)

\section{Bibliografia}

BARO, D, Soares, S., Fontoura, N. Pinheiro, L. Desigualdade Racial e Construção Institucional; ( 1995-2005) IPEA/ 2009

Cardoso, Adalberto. (2012). Juventude, Desigualdades e o Futuro do Rio de Janeiro, Instituto de Estudos Sociais e Políticos (Iesp),

CASTELLS, Manuel. O poder da identidade. Tradução Klauss Brandini Gerhardt. 2.ed. São Paulo: Paz e Terra, 2000.

CASTRO, Nadya e GUIMARÃES, Antonio; 1993 - “Desigualdades Raciais no Mercado e nos Locais de Trabalho" in Estudos Afro- Asiáticos n.. 24, Rio de Janeiro.

CHEVALIER, Louis, (1978) Classes Laborieuses et Classes Dangereuses.Paris : Hachett.

DEMAZIÈRE, Didier. (2006) Trajetórias Profissionais e Formas Identitárias :Uma Teorização.in, Guimarães, Nádya e Hirata, Helena. Trajetórias, Identidades e Mobilizações. São Paulo: Editora SENAC.

DUBAR, Claude, (1987) L'Autre Jeunesse.Lille : Presses Universitaire de Lille. DIEESE/SEADE(http://www.redebrasilatual.com.br/temas/trabalho/2011/11/difere ncas-no-mercado-de-trabalho-seguem-desfavoraveis-a-negros-confirma-estudo GALLAND, Olivier. (1999). Les Jeunes.Paris: La Decouvert

GANDINI,Camilla, (2010) .Projeto Urbal - Políticas Locais de Prevenção da Violência Notas sobre a responsabilidade social das empresas em santo amaro: análise do envolvimento das empresas em programas governamentais para o emprego juvenil

HENRIQUES, Ricardo - Desigualdade racial no Brasil: Evolução das Condições de Vida na Década de 90 - Texto para discussão no 807

IPEA -2001- Rio de Janeiro ( Disponível no site www.prsp.mpf.gov.br em

22/10/2012)

HASENBALG. C. e SILVA. N. (1988.)Estrutura Social, Mobilidade E Raça. Rio de Janeiro, Editora Vértice.

- (1999) Perspectivas sobre Raça e Classe no Brasil, in Cor e Estratificação Social: Rio : ContraCapa

HOLLANDA, Filho Fernando http://oglobo.globo.com/economia/um-quinto-dosjovens-nem-estuda-nem-trabalha-nem-busca-emprego-6109028\#ixzz2AAbJHt9x Ignez Helena Oliva Perpétuo1 Raça e acesso às ações prioritárias na Agenda Da Saúde Reprodutiva 1 UFMG/Departamento de Demografia/CEDEPLAR; www.abep.nepo.unicamp.br/docs/anais/pdf/2000/.../rept14 
Marília Salles Falci Medeiros

MARUANI,Margaret ( 2002). Les Mécomptes Du Chômage. Paris : Bayard.

MESQUITA, Marcos, O desemprego juvenil e a crise social no Brasil atual, Revista Eletrônica do Laboratório de Estudos Contemporâneos, UNICAMP

NERI, Marcelo, Economia e Negócios - Informações da Agência o Estado de São Paulo. disponível no estadão .com.br-22/09/2012

PERPÉTUO, Ignez Helena Oliva, Junho 2000; Raça e acesso às ações prioritárias na agendada saúde reprodutiva. UFMG/Departamento de Demografia/CEDEPLAR.

PAIXÃO, Marcelo Entrevista, “ Afrobrasileiros e suas lutas Publicado em Quinta, 12 Janeiro 2012 12:45)"

Pastore, José E Silva, Nelson Do Valle. Mobilidade social no Brasil. São Paulo, Makron Books, 2000.

SANCHIS, Enric. Da Escola ao Desemprego. Rio de Janeiro: editora Agir, 1997.

Salais, Robert; Baverz ,N.; Reynaud ,B. ( 1996) L'Invention du Chõmage, Paris. Puf.

VALLADARES, Lícia do Prado. Cem anos repensando a pobreza (urbana) no Brasil. In: BOSCHI, R.(Org.). Corporativismo e desigualdade: a construção do espaço público no Brasil. Rio de Janeiro: Rio Fundo Editora, 1991. p.81-112.

\section{Nota:}

(1) Definições de Desemprego. No Brasil, além do IBGE, a Fundação Sistema Estadual de Análise de Dados (Seade) e o Departamento Intersindical de Estatística e Estudo Sócio-Econômicos (Dieese) medem a taxa de desemprego. O IBGE utiliza o critério de desemprego aberto, no qual somente as pessoas que no período de referência estavam disponíveis para trabalhar e realmente procuraram trabalho são consideradas desempregadas. O cálculo é feito com base em dados de seis regiões metropolitanas: São Paulo, Rio de Janeiro, Belo Horizonte, Porto Alegre, Salvador e Recife. O Seade e o Dieese - que realizam a pesquisa no Distrito Federal e nas regiões metropolitanas de São Paulo, Porto Alegre, Belo Horizonte, Salvador e Recife - adotam o critério de desemprego total, que engloba também o desemprego oculto. Nessa categoria estão aqueles que não procuraram emprego por desalento ou porque estavam exercendo um trabalho precário. Esses cálculos levam a resultados muito diferentes. Na região metropolitana de São Paulo, por exemplo, enquanto o IBGE aponta em agosto de 2000 uma taxa de desemprego aberto de $7,55 \%$, a Fundação Seade e o Dieese chegam a uma taxa de desemprego total de $17,7 \%$. 